\title{
Aldehyde dehydrogenase 1 , a target of miR-222, is expressed at elevated levels in cervical cancer
}

\author{
CHANGDE LIU ${ }^{1}$, YAN ZHANG ${ }^{2}$, SHANGHUA LIANG ${ }^{3}$ and YUHUA YING ${ }^{4}$ \\ ${ }^{1}$ Clinical Laboratory, The Hui People Hospital of Beijing, Beijing 100054; ${ }^{2}$ Clinical Laboratory, Yuquan Hospital of \\ Tsinghua University, Beijing 100049; ${ }^{3}$ Department of Pathology, Beijing Dian Medical Testing Laboratory Co., \\ Beijing 102609; ${ }^{4}$ Department of Gynaecology, Yuquan Hospital of Tsinghua University, Beijing 100049, P.R. China
}

Received December 17, 2018; Accepted September 4, 2019

DOI: $10.3892 /$ etm.2020.8425

\begin{abstract}
The aim of the present study was to investigate the expression of microRNA-222 (miR-222) and aldehyde dehydrogenase 1 (ALDH1) in tissues and peripheral blood of cervical cancer patients, and to elucidate their underlying mechanisms of action. Tumor tissues and tumor-adjacent tissues were obtained from 33 cervical cancer patients and peripheral blood was obtained from these patients and 28 healthy subjects. The expression of miR-222 and ALDH1 mRNA was evaluated by reverse transcription-quantitative polymerase chain reaction (RT-qPCR). To examine the levels of ALDH1 protein in tissues and blood, western blotting and ELISA were used. To confirm a direct interaction between miR-222 and ALDH1 mRNA, a dual luciferase reporter assay was performed. HeLA cells were transfected with agomiR-222 and expression of ALDH1 in the cells was measured by RT-qPCR and western blotting. MTT assay was preform to investigate the proliferation of HeLA cells. Expression of ALDH1 mRNA and protein was elevated in cervical cancer tissues and peripheral blood from patients compared with tumor-adjacent tissues and healthy controls, while the expression of miR-222 was reduced. Upregulation of miR-222 inhibited HeLA cell proliferation possibly due to a reduction in the expression of ALDH1. A dual luciferase reporter assay showed that miR-222 can bind with the 3'-untranslated seed region of ALDH1 mRNA to regulate its expression. miR-222 regulation of ALDH1 expression may play a role in the prevention of cervical cancer.
\end{abstract}

\section{Introduction}

Cervical cancer is one of the most common gynecological malignancies, accounting for $10 \%$ of all gynecological

Correspondence to: Dr Yuhua Ying, Department of Gynaecology, Yuquan Hospital of Tsinghua University, 5 Shijingshan Road, Beijing 100049, P.R. China

E-mail: ha6171@163.com

Key words: aldehyde dehydrogenase 1, microRNA-222, cervical cancer cancers, and its incidence accounts for approximately 5\% of all tumors (1). Worldwide, there are nearly 500,000 new cases and approximately 270,000 patients die from cervical cancer each year (2). The majority of both the new and the fatal cases of cervical cancer occur in developing countries (3). The annual incidence of cervical cancer is increasing at a rate of 2-3\% per year in China and the disease is increasingly seen in younger patients. The number of new cases each year in China accounts for $1 / 3$ of the worldwide increase (4).

Surgery and radiotherapy are at present the main treatments for cervical cancer, however, surgery is effective only at early stages of the disease (5). The most common pathological type of cervical cancer is squamous cell carcinoma, accounting for $80-85 \%$ of cases (6). The main pathways for the metastasis of cervical cancer are direct spread and lymphatic metastasis (6). Distant metastasis largely occurs through lymphatic metastasis (6). Multidrug resistance (MDR) is the main cause of chemotherapy failure in cervical cancer patients, and MDR has become one of the most difficult problems for cervical cancer treatment (7). Once distant metastasis and local recurrence of cervical cancer occur, the patient survival rate is significantly reduced (8). It is therefore of great practical significance to search for new treatment targets and prognostic molecular markers for cervical cancer.

Aldehyde dehydrogenase 1 (ALDH1) is associated with the occurrence and development of many human tumors. Increased expression of ALDH1 usually suggests an insensitivity to chemotherapy and poor prognosis $(9,10)$. ALDH1 also plays a role in regulating apoptosis, but the mechanism underlying this is not clear (11-13).

The expression of multiple microRNA (miR) molecules and proteins in cervical cancer suggests that miRs may play important roles in the regulation of disease-related proteins (14). miR-222 is found to be abnormally expressed in many tumor tissues (15-17), and is associated with MDR $(18,19)$. However, the regulatory relationship between miR-222 and ALDH1 in cervical cancer has, to the best of our knowledge, not yet been reported.

The current study aimed to investigate the expression of miR-222 and ALDH1 in tumor tissues and blood from cervical cancer patients, and to elucidate the relationship between them. 


\section{Materials and methods}

Patients. A total of 33 patients with cervical cancer who received surgical treatment at Yuquan Hospital of Tsinghua University (Beijing, China) between January 2015 and March 2018 were included in the present study. The age range of the patients was 27-60 years, and the median age was 42.6 years.

Tumor tissues were collected from cervical cancer patients as the experimental group and tumor-adjacent tissues were collected as a control group. Peripheral blood was collected from the same 33 patients and from 28 healthy female subjects who underwent physical examination and had no history of use of hormones, traditional Chinese medicine or chemotherapy or radiotherapy. The age range of the healthy subjects was 26-63 years, and the median age was 43.5 years.

Cervical cancer was diagnosed by hospital pathologists according to the European Society for Medical Oncology Clinical Practice Guidelines for diagnosis, treatment and follow-up of cervical cancer (20). All patients had no prior diagnosis of cervical cancer, and had no history of use of steroids, traditional Chinese medicine, radiotherapy or chemotherapy before surgery.

All procedures used in the current study were approved by the Ethics Committee of Tsinghua University. All patients or their families signed written informed consent forms.

Cells. Human HeLA cells (The Cell Bank of Type Culture Collection of the Chinese Academy of Sciences) were cultured in DMEM (cat. no. SH30022.01; Hyclone, Thermo Fisher Scientific, Inc.) containing 10\% fetal bovine serum (FBS; E600001; Sangon Biotech Co., Ltd.) at $37^{\circ} \mathrm{C}$ and $5 \% \mathrm{CO}_{2}$. The cells $\left(3 \times 10^{5}\right)$ in logarithmic growth phase were seeded onto 24-well plates one day before transfection, and cultured in antibiotic-free nutrient mixture F12/DMEM medium (cat. no. 11320-033; Thermo Fisher Scientific, Inc.) supplemented with 10\% FBS until they reached $70 \%$ confluency. In the first vial, $1 \mu \mathrm{l}$ agomiR-negative control (agomiR-NC; $20 \mathrm{pmol} / \mu \mathrm{l} ; 5$ '-UUCUCCGAACGUGUCACG UTT-3' and 3'-TTAAGAGGCUUGCACAGUGCA-5'; Hanbio Biotechnology Co., Ltd.) or agomiR-222 (20 pmol/ $\mu \mathrm{l}$; 5'-CUC AGUAGCCAGUGUAGAUCCU-3' and 3'-GAGUCAUCG GUCACAUCUAGGA-5'; Hanbio Biotechnology Co., Ltd.) was mixed with $50 \mu$ l Opti MEM. In the second vial, $1 \mu \mathrm{l}$ Lipofectamine $^{\circledR} 3000$ (Thermo Fisher Scientific, Inc.) was mixed with $50 \mu \mathrm{l}$ Opti MEM medium. After $5 \mathrm{~min}$, the two vials were mixed an incubated for $20 \mathrm{~min}$ at room temperature. Cells in their respective groups were treated with the mixtures. Six hours later, the medium was replaced with F12/DMEM medium containing $10 \%$ FBS. The cells were collected for use after $48 \mathrm{~h}$ of incubation.

Reverse transcription-quantitative PCR (RT-qPCR). Tissue samples $(100 \mathrm{mg})$ were ground into a powder in liquid nitrogen and lysed with $1 \mathrm{ml} \mathrm{TRIzol}{ }^{\circledR}$ reagent (Thermo Fisher Scientific, Inc.) following the manufacturer's instructions. Plasma $(100 \mu \mathrm{l})$ or cells $\left(3 \times 10^{6}\right)$ were directly lysed with $1 \mathrm{ml}$ TRIzol reagent. Total RNA was extracted using the phenol chloroform method (21). The quality of extracted mRNA and miRNA was assessed by gel electrophoresis. To obtain cDNA, $1 \mu \mathrm{g}$ RNA was reverse-transcribed and the resulting cDNA was stored at $-20^{\circ} \mathrm{C}$ until use. The TIANScript II cDNA First Strand Synthesis kit (Tiangen Biotech Co., Ltd.) was used for reverse transcription of mRNA, while the miRcute miRNA cDNA First Strand Synthesis kit (Tiangen Biotech Co., Ltd.) was employed for reverse transcription of miRNA according to the manufacturer's manual. The temperature protocol was $30 \mathrm{~min}$ of incubation at $55^{\circ} \mathrm{C}$.

The SuperReal PreMix (SYBR Green) RT-qPCR kit (Tiangen Biotech Co., Ltd.) was used to determine ALDH1 mRNA expression levels, and GAPDH was used as the internal reference. The sequences of ALDH1 and GAPDH primers are listed in Table I. The reaction mixture $(20 \mu \mathrm{l})$ was composed of $10 \mu \mathrm{l}$ SYBR Premix EXTaq, $0.5 \mu \mathrm{l}$ forward primer, $0.5 \mu \mathrm{l}$ reverse primer, $2 \mu \mathrm{l}$ cDNA and $7 \mu 1 \mathrm{ddH}_{2} \mathrm{O}$. The following thermocycling conditions were used: Initial denaturation at $95^{\circ} \mathrm{C}$ for $30 \mathrm{sec} ; 39$ cycles of denaturation at $95^{\circ} \mathrm{C}$ for $10 \mathrm{sec}$, annealing at $60^{\circ} \mathrm{C}$ for $30 \mathrm{sec}$ and elongation at $72^{\circ} \mathrm{C}$ for $15 \mathrm{sec}$; and a final extension at $72^{\circ} \mathrm{C}$ for $5 \mathrm{~min}$ in an iQ5 thermal cycler (Bio-Rad Laboratories, Inc.). The $2^{-\Delta \Delta C q}$ method (22) was used to determine relative expression of ALDH1 mRNA against GAPDH. Each sample was tested in triplicate.

The level of miR-222 was determined using the miRcute miRNA RT-PCR kit (Tiangen Biotech Co., Ltd.), and U6 was used as the internal reference. The primer sequences of miR-222 and U6 are listed in Table I. The reaction mixture (20 $\mu$ l) contained $10 \mu 1$ RT-qPCR-Mix, $0.5 \mu 1$ forward primer, $0.5 \mu 1$ reverse primer, $2 \mu 1 \mathrm{cDNA}$ and $7 \mu 1 \mathrm{ddH}_{2} \mathrm{O}$. The following thermocycling conditions were used: Initial denaturation at $95^{\circ} \mathrm{C}$ for $5 \mathrm{~min} ; 40$ cycles of denaturation at $95^{\circ} \mathrm{C}$ for $30 \mathrm{sec}$, annealing at $60^{\circ} \mathrm{C}$ for $35 \mathrm{sec}$ and elongation at $72^{\circ} \mathrm{C}$ for $20 \mathrm{sec}$ in an iQ5 thermal cycler. The $2^{-\triangle \Delta \mathrm{Cq}}$ method was used to calculate the relative expression of miR-222 against U6. Each sample was tested in triplicate.

Western blotting. Before lysis, $100 \mathrm{mg}$ tissue samples were first frozen in liquid nitrogen and then ground into powder, and cells $\left(1 \times 10^{6}\right)$ were trypsinized and collected. Then, tissue samples or cells were lysed with $600 \mu 1$ RIPA lysis buffer (Beyotime Institute of Biotechnology) for $30 \mathrm{~min}$ on ice. After centrifugation at $1,200 \mathrm{xg}$ and $4^{\circ} \mathrm{C}$ for $10 \mathrm{~min}$, supernatant was collected and used to determine protein concentration (BCA protein concentration determination kit; cat. no. RTP7102; Real-Times (Beijing) Biotechnology Co., Ltd.). After mixing the samples with $5 \mathrm{X}$ sodium dodecyl sulfate (Beyotime Institute of Biotechnology) loading buffer, the samples were denatured in boiling water for $5 \mathrm{~min}$. Afterwards, the samples $(20 \mu \mathrm{g})$ underwent $10 \%$ gel sodium dodecyl sulfate-polyacrylamide gel electrophoresis at $100 \mathrm{~V}$. Proteins were then transferred to PVDF membranes on ice (100 V, $2 \mathrm{~h})$ and blocked with $5 \%$ non-fat milk at room temperature for $1 \mathrm{~h}$. The membranes were treated with monoclonal rabbit anti-human ALDH1 (1:2,000; cat. no. ab52492; Abcam) or $\beta$-actin (1:5,000; cat. no. ab129348; Abcam) primary antibodies at $4^{\circ} \mathrm{C}$ overnight. After washing ( 3 times, each for $15 \mathrm{~min}$ ), the membranes were incubated with goat anti-rabbit horseradish peroxidase-conjugated secondary antibody (1:3,000; cat. no. ab6721; Abcam) for $1 \mathrm{~h}$ at room temperature. After washing ( 3 times, each for $15 \mathrm{~min}$ ), the membrane was developed with an ECL Western Blotting Substrate kit (cat. no. ab65623; Abcam). Imaging signals were acquired and analyzed using Image Lab software 
Table I. Primer sequences.

Primer aequence $\left(5^{\prime}-3^{\prime}\right)$

\begin{tabular}{|c|c|c|}
\hline Target & Forward & Reverse \\
\hline ALDH1 & CCGTGGCGTACTATGGATGC & CGCAATGTTTTGATGCAGCCT \\
\hline GAPDH & TGTTCGTCATGGGTGTGAACC & ATGGACTGTGGTCATGAGTCC \\
\hline miR-222 & CGCAGCTACATCTGGCTACTG & GTGCAGGGTCCGAGGT \\
\hline U6 & CGCTTCGGCAGCACATATAC & CAGGGGCCATGCTAATCTT \\
\hline
\end{tabular}

ALDH1, aldehyde dehydrogenase-1; miR, microRNA.

(version 3.0; Bio-Rad Laboratories, Inc.). Relative amounts of target proteins were expressed in comparison to $\beta$-actin.

Enzyme-linked immunosorbent assay (ELISA). An ALDH1 ELISA kit (cat. no. sE94824Hu; Shanghai Wuhao Bio-tech Co., Ltd.) was used to measure ALDH1 concentrations. Standards (50 $\mu \mathrm{l})$ and samples (10 $\mu \mathrm{l}$ serum and $40 \mu \mathrm{l}$ diluent) were added into predefined wells of microplates, and blank wells were left empty. Horseradish peroxidase-labelled conjugates (100 $\mu \mathrm{l})$ were added into the wells for standards and samples. The plates were then sealed before incubation at $37^{\circ} \mathrm{C}$ for $1 \mathrm{~h}$. After washing the plates (5 times), $50 \mu \mathrm{l}$ substrate A and $50 \mu \mathrm{l}$ substrate B were added into each well. After incubation at $37^{\circ} \mathrm{C}$ for $15 \mathrm{~min}, 50 \mu \mathrm{l}$ stop solution was added, and absorbance was determined at $450 \mathrm{~nm}$.

Bioinformatics. miRanda (August 2010 Release; http://www.microrna.org/microrna/home.do), TargetScan (v6.2; http://www.targetscan.org), PiTa (v6; http://genie. weizmann.ac.il/pubs/mir07/mir07_data.html), RNAhybrid (September 18 2017; http://bibiserv.techfak.uni-bielefeld. de/rnahybrid/) and PICTA (March 26, 2007; http://pictar. mdc-berlin.de/) were used to predict target genes that may be regulated by miR-222.

Dual-luciferase reporter assay. Wild-type and mutant seed regions of miR-222 in the 3'-UTR of the ALDH1 gene were chemically synthesized in vitro, and then cloned into pMIR-REPORT luciferase reporter plasmids (Ambion; Thermo Fisher Scientific, Inc.). Plasmids (0.8 $\mu \mathrm{g})$ with wild-type or mutant 3'-UTR sequences were co-transfected with agomiR-222 (100 nM; forward, 5'-AGCUACAUCUGG CUACUGGGU-3'; reverse, 3'-UCGAUGUAGACCGAUGAC CCA-5'; Sangon Biotech Co., Ltd.) using Lipofectamine 2000 (Thermo Fisher Scientific, Inc.) into 293T cells (The Cell Bank of Type Culture Collection of the Chinese Academy of Sciences). For control, 293T cells were transfected with agomiR-negative control (NC; scrambled sequence; forward, 5'-UUCUCCGAACGUGUCACGUTT-3'; reverse, 3'-TTA AGAGGCUUGCACAGUGCA-5'; Sangon Biotech Co., Ltd.). After $24 \mathrm{~h}$ incubation, the cells were treated with a dual-luciferase reporter assay kit (Promega Corporation) according to the manufacturer's manual, and luminescence intensity was measured using a luminometer (GloMax 20/20; Promega Corporation). The luminescence values of each group of cells were measured using Renilla luminescence activity as an internal reference.

MTT assay. To examine proliferation, $20 \mu \mathrm{l}$ MTT (5 g/l; cat. no. JRDC000003, JRDUN Biotechnology Co., Ltd.) was added at 24, 48 and $72 \mathrm{~h}$ after transfection, followed by incubation at $37^{\circ} \mathrm{C}$ for $4 \mathrm{~h}$. After removing medium, dimethyl sulfoxide was added at a volume of $150 \mu \mathrm{l}$ per well to dissolve purple crystals. The absorbance in each well was measured at $490 \mathrm{~nm}$ with a microplate reader and cell proliferation curves were plotted against time.

Statistical analysis. SPSS version 20.0 statistical software (IBM Corp.) was used for statistical analysis. Data are presented as mean \pm standard deviation and were tested for normality. Measurement data were analyzed using one-way ANOVA for multiple groups, with Student-Newman-Keuls post-hoc tests subsequently used. Comparisons between two groups were performed using a paired or unpaired Student's t-test. $\mathrm{P}<0.05$ indicated a statistically significant difference.

\section{Results}

Expression of ALDH1 mRNA is elevated in cervical cancer. RT-qPCR was performed to measure ALDH1 mRNA expression. The level of ALDH1 mRNA in tumor tissues was significantly higher than that in tumor-adjacent tissues $(\mathrm{P}<0.01$; Fig. 1A), and the level of ALDH1 mRNA in peripheral blood from cervical cancer patients was significantly higher than that from control subjects $(\mathrm{P}<0.01$; Fig. 1B). These results indicate that the expression of ALDH1 mRNA was increased in cervical cancer.

Expression of ALDH1 protein is elevated in cervical cancer. To determine ALDH1 protein expression in tissues and blood, western blotting and ELISA were used. The data showed that the level of ALDH1 protein in tumor tissues from cervical cancer patients was significantly higher than that in tumor-adjacent tissues ( $\mathrm{P}<0.05$; Fig. $2 \mathrm{~A})$. Additionally, the level of ALDH1 protein in peripheral blood from cervical cancer patients was significantly elevated when compared with healthy control subjects $(\mathrm{P}<0.05$; Fig. 2B). This result indicated that ALDH1 protein level was increased in cervical cancer and is consistent with the study findings regarding ALDH1 mRNA. 

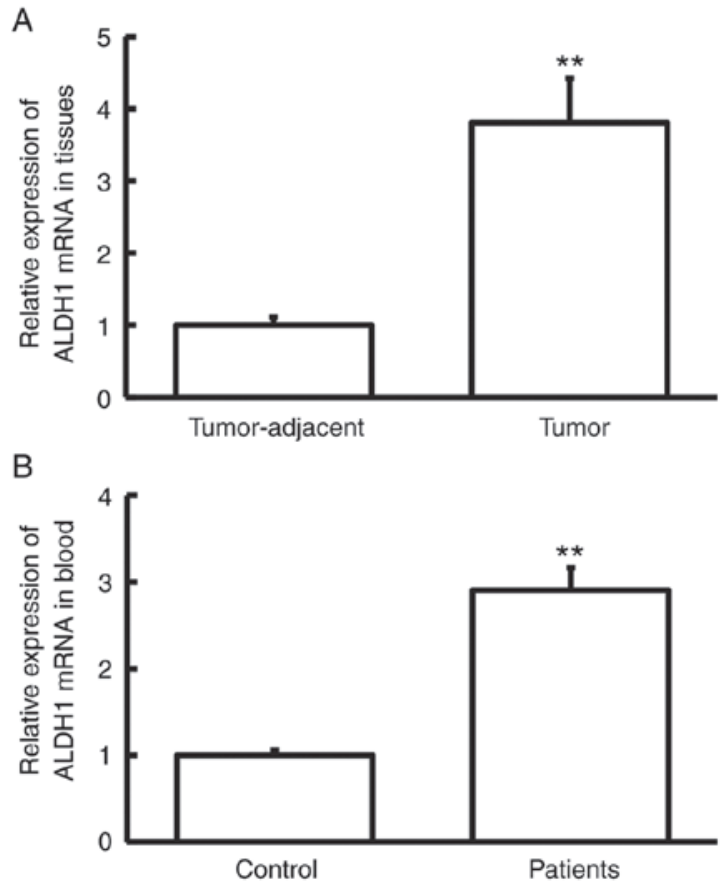

Figure 1. Expression of ALDH1 mRNA in tissues and peripheral blood. (A) Expression of ALDH1 mRNA in tumor-adjacent and tumor tissues from cervical cancer patients as determined by RT-qPCR. Paired Student's t-test was used for comparison between the two groups. ${ }^{* *} \mathrm{P}<0.01$ compared with tumor-adjacent tissues. (B) Expression of ALDH1 mRNA in peripheral blood from healthy subjects (control) and cervical cancer patients as determined by RT-qPCR. Unpaired Student's t-test was used for comparison between the two groups. ${ }^{* *} \mathrm{P}<0.01$ compared with control. ALDH1, aldehyde dehydrogenase-1; control, healthy subjects; RT-qPCR, reverse transcription-quantitative PCR.

Expression of miR-222 in cervical cancer is reduced. To study the expression of miR-222, RT-qPCR was performed. The data showed that miR-222 expression in tumor tissues was significantly lower than that in tumor-adjacent tissues $(\mathrm{P}<0.01$; Fig. 3A), and that miR-222 levels in peripheral blood from cervical cancer patients were significantly lower than those in a healthy control group $(\mathrm{P}<0.05$; Fig. 3B). These data suggest that miR-222 expression was reduced in cervical cancer.

miR-222 regulates the expression of ALDH1 mRNA by binding to the ALDH mRNA 3'-UTR seed region. Bioinformatics prediction showed that ALDH1 was a potential target gene of miR-222 (Fig. 4A). To study miR-222 interaction with ALDH1 mRNA, a dual-luciferase reporter assay was employed. Luminescence intensity of cells in the wild-type group was significantly lower than that in the negative control group $(\mathrm{P}<0.01)$, while luminescence intensity in the mutant group was not significantly different from that in the negative control group (Fig. 4B). These data indicate that miR-222 regulated expression of ALDH1 mRNA by binding with its 3'-UTR seed region.

Overexpression of miR-222 reduces the proliferation of HeLA cells possibly by a reduction in the expression of $A L D H 1$. To test how miR-222 affects cell proliferation, HeLA cells were transfected with agomiR-NC or agomiR-222. The data showed that the level of miR-222 in HeLA cells of the agomiR-222 group was significantly higher than that in the
A
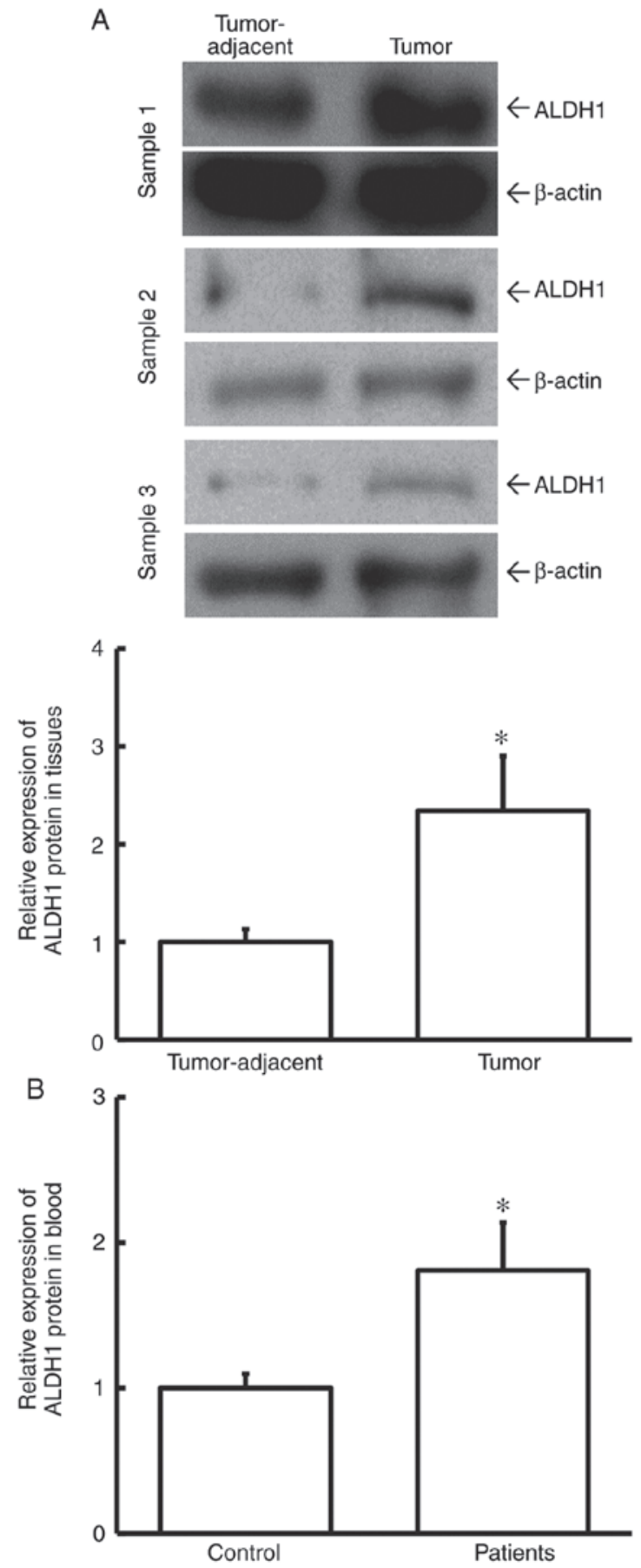

Figure 2. Expression of ALDH1 protein in tissues and peripheral blood. (A) Expression of ALDH1 protein in tumor-adjacent and tumor tissues from cervical cancer patients. Paired Student's t-test was used for comparison between the two groups. ${ }^{*} \mathrm{P}<0.05$ compared with tumor-adjacent tissues as determined by western blotting. (B) Expression of ALDH1 protein in peripheral blood from control and cervical cancer patients as determined by ELISA. Unpaired Student's t-test was used for comparison between the two groups. "P $<0.05$ compared with control. ALDH1, aldehyde dehydrogenase-1; control, healthy subjects.

agomiR-NC group ( $\mathrm{P}<0.01$; Fig. 5A). In addition, expression levels of both ALDH1 mRNA and protein in HeLA cells of the agomiR-222 group were significantly lower than those in the agomiR-NC group ( $\mathrm{P}<0.05$; Fig. $5 \mathrm{~B}$ and $\mathrm{C})$. MTT assay showed that the proliferation of HeLA cells of the agomiR-222 group was significantly slower than that of the agomiR-NC group 

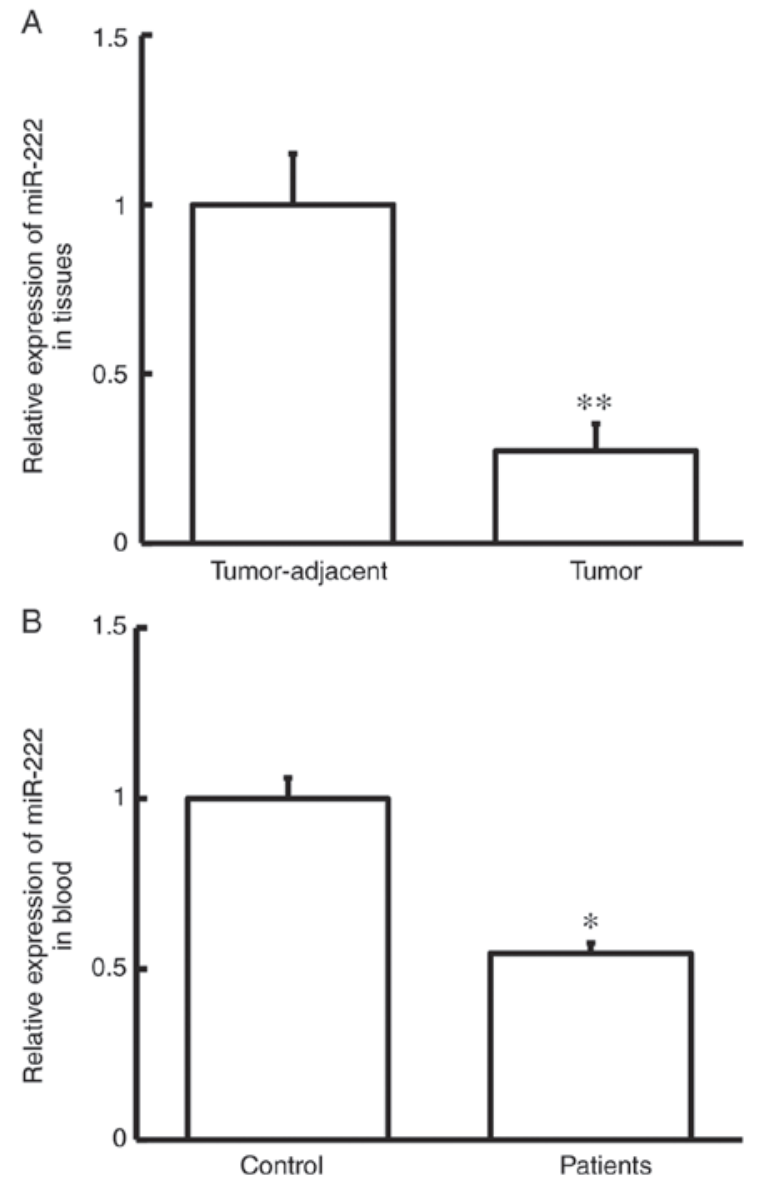

Figure 3. Expression of miR-222 in tissues and peripheral blood. (A) Expression of miR-222 in tumor-adjacent and tumor tissues from cervical cancer patients as determined by RT-qPCR. Paired Student's t-test was used for comparison between the two groups. ${ }^{* *} \mathrm{P}<0.01$ compared with tumor-adjacent tissues. (B) Expression of miR-222 in peripheral blood from control and cervical cancer patients as determined by RT-qPCR. Unpaired Student's t-test was used for comparison between the two groups. " $\mathrm{P}<0.05$ compared with control. Control, healthy subjects; miR-222, microRNA-222; RT-qPCR, reverse transcription quantitative polymerase chain reaction.

$(\mathrm{P}<0.01$ at 72 h; Fig. 5D). These data suggest that upregulation of miR-222 reduces the proliferation of HeLA cells, possibly by reducing the expression of ALDH1.

\section{Discussion}

Cervical cancer is the second most common female malignancy in the world after breast cancer (23). A major challenge in the treatment of cervical cancer is the invasion and metastasis. Lymphatic metastasis is common in cervical cancer, and is closely related to the prognosis of patients (23). It is an important basis for judging the prognosis of patients and treatment options (23). Chemotherapy plays an important role in the treatment of cervical cancer. However, the tolerance of cervical cancer cells to chemotherapeutic drugs limits their efficacy. Forms of drug resistance of tumor cells to chemotherapeutic drugs include natural or primary resistance, acquired or secondary resistance and MDR or cross resistance (24). ALDH1 is a protein related to drug resistance and apoptosis. Proliferation, colony-formation, adhesion, migration and invasion of breast cancer cells are upregulated
A
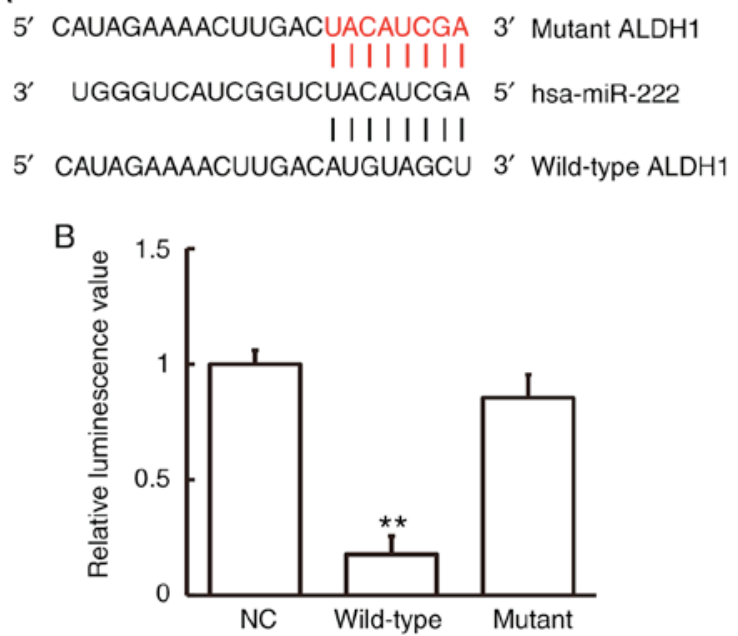

Figure 4. Direct interaction between miR-222 and ALDH1. (A) miRanda, TargetScan, PiTa, RNAhybrid and PICTA were employed to predict target genes that may be regulated by miR-222. ALDH1 was predicted to be one such target. Red bases demonstrate those that do not match with hsa-miR-222. (B) Interaction between miR-222 and ALDH1 mRNA was confirmed using a dual-luciferase reporter assay. Plasmids with wild-type or mutant 3'-untranslated region sequences were co-transfected with agomiR-222 into 293T cells. As a control, 293T cells were transfected with agomiR-NC. Renilla luminescence activity was used as an internal reference. ${ }^{* *} \mathrm{P}<0.01$ compared with the NC group. ALDH1, aldehyde dehydrogenase-1; miR, microRNA; $\mathrm{NC}$, negative control.

by ALDH1 overexpression in vitro (25). Increased expression of ALDH1 in human breast cancer is associated with poor prognosis (11). It has also been discovered that the percentage of African breast cancer patients with positive ALDH1 expression is about $48 \%$ (12). The percentage of patients receiving cyclophosphamide-based chemotherapy who have positive expression of ALDH1 in cancer tissues is 61\%, suggesting that ALDH1 may be a reference index reflecting biological behavior of breast cancer (13). ALDH1 plays a role in regulating apoptosis, though the underlying mechanism is not yet clear. Several studies have shown that lowering the level of ALDH1 can cause apoptosis $(26,27)$. The expression of ALDH1 is also associated with neurogenic locus notch homolog 3 (28), transforming growth factor- $\beta$ (29) and nuclear factor- $\kappa \mathrm{B}$ (30) signaling pathways. In cervical cancer, the expression of ALDH1 is closely related to the Erk1/2 and Akt signaling pathways (31). Based on these data, it is hypothesized that high expression of ALDH1 contributes to drug resistance in cervical cancer. The results of the present study show that expression levels of ALDH1 mRNA and protein were elevated in cervical cancer tissues and peripheral blood from cervical cancer patients when compared with controls.

Using prediction by bioinformatics, it was discovered that the miR-222 sequence is closely associated with ALDH1, and may possibly be an upstream miRNA that regulates ALDH1 expression. miR-222 may cut the mRNA of ALDH1 to inhibit its translation (32). Regulation by miRNA promotes the upor downregulation of mRNA and plays an important role in the occurrence and development of diseases (33). It has been reported that miR-222 can target matrix metallopeptidase 1 to regulate the biological functions of tongue squamous carcinoma cells (34). In addition, miR-222 can regulate 

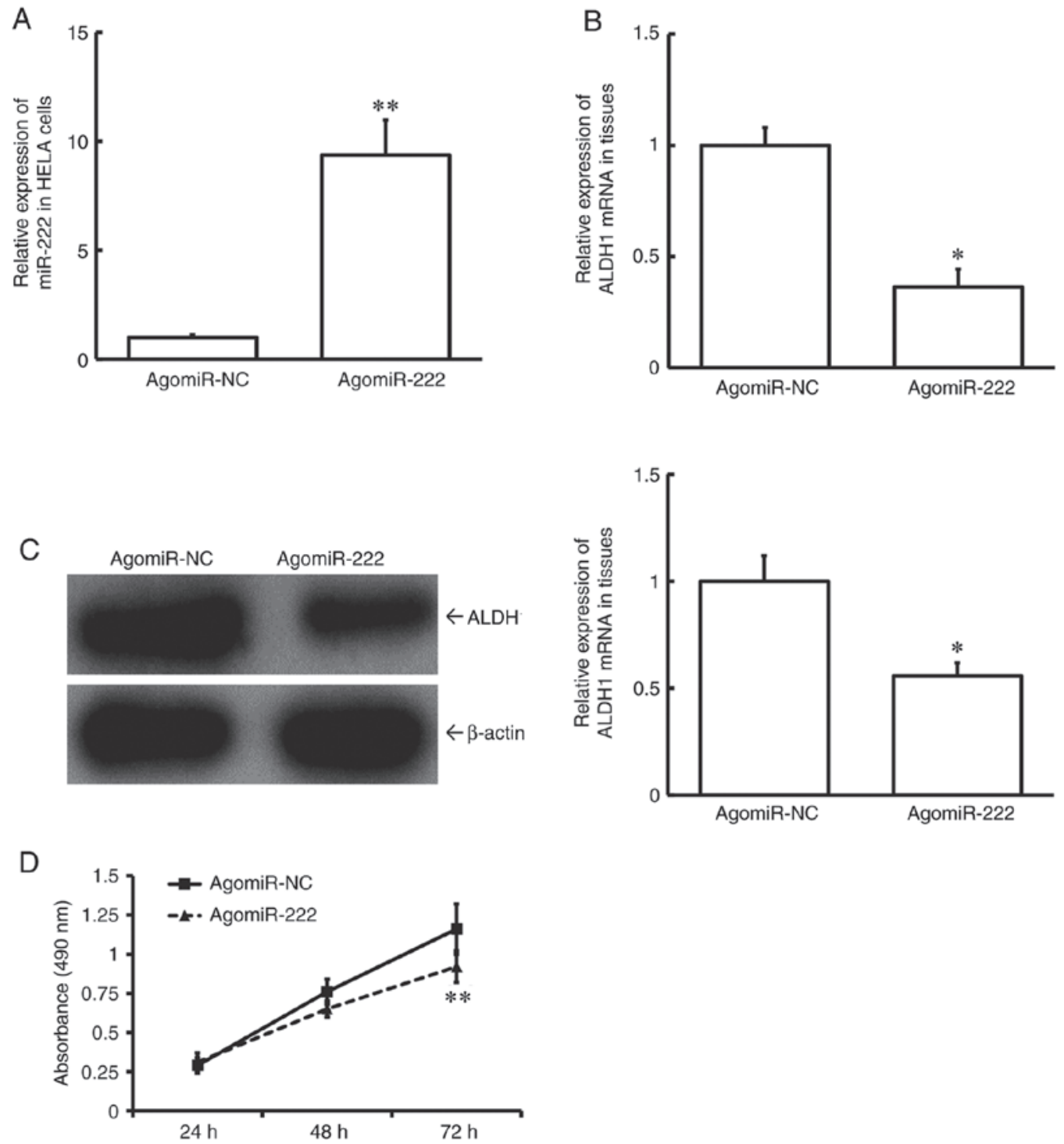

Figure 5. Effect of overexpression of miR-222 on the proliferation of cervical cancer cells. (A) Expression of miR-222 in HeLA cells transfected with agomiR-NC or agomiR-222 as determined by RT-qPCR. (B) Expression of ALDH1 mRNA in HeLA cells transfected with agomiR-NC or agomiR-222 as determined by RT-qPCR. (C) Expression of ALDH1 protein in HeLA cells transfected with agomiR-NC or agomiR-222 as determined by western blotting. (D) Proliferation of HeLA cells transfected with agomiR-NC or agomiR-222 as determined by MTT assay. ${ }^{*} \mathrm{P}<0.05$ and ${ }^{* * *} \mathrm{P}<0.01$ compared with agomiR-NC group. Unpaired Student's t-test was used for comparison between the two groups. ALDH1, aldehyde dehydrogenase-1; miR, microRNA; NC, negative control; RT-qPCR, reverse transcription quantitative polymerase chain reaction.

dual specificity mitogen-activated protein kinase and tumor necrosis factor-related apoptosis-inducing ligand pathways of thyroid follicular epithelial cells (35). miR-222 can also affect the progression of gastric cancer by regulating its target gene cyclin dependent kinase inhibitor 1B (36). Abnormal expression of miR-222 was also found in a transgenic mouse gastric cancer model (37). miR-222 also has a unique regulatory role in ovarian cancer-associated macrophages (38). These reports indicate that miRNA-222 is closely related to the occurrence and development of tumors.

In the present study reduced expression levels of miR-222 and increased expression levels of ALDH1 were discovered in tumor tissues and peripheral blood from cervical cancer patients. These findings suggest that cleavage of ALDH1 by miR-222 may be reduced by downregulation of miR-222. In order to further study the underlying molecular mechanisms by which miR-222 and ALDH1 regulate cervical cancer cells, HeLA cells were transfected with agomiR-222, leading to overexpression of miR-222, and downregulation of ALDH1 mRNA and protein when compared with controls. The proliferation of HeLA cells was also inhibited following transfection with agomiR-222 compared with agomiR-NC. The results of a dual luciferase reporter assay revealed that miR-222 may directly bind with the 3'-UTR seed region of ALDH1 mRNA to regulate its expression.

A limitation of the present study is that only one type of cells was used in the in vitro experiments. This work will be expanded on in future studies using a variety of additional cell types to confirm these findings.

In conclusion, the present study demonstrated that the expression of ALDH1 was elevated and that of miR-222 was reduced in cervical cancer tissues and peripheral blood when compared with controls. miR-222 may prevent the occurrence and development of cervical cancer by regulating the proliferation of tumor cells via ALDH1. 


\section{Acknowledgements}

The authors wish to thank Professor Shuzhen $\mathrm{Xu}$ from Friendship Hospital Affiliated to Capital Medical University (Beijing, China) for her suggestions and instructions on the design of the study.

\section{Funding}

No funding was received.

\section{Availability of data and materials}

The datasets used and/or analyzed during the current study are available from the corresponding author on reasonable request.

\section{Authors' contributions}

The final version of the manuscript was read and approved by all authors, and each author believes that the manuscript represents honest work. CL and YY collaborated to design the study. CL, YZ and SL were responsible for performing experiments. CL and YY analyzed the data. All authors collaborated to interpret results and develop the manuscript.

\section{Ethics approval and consent to participate}

All procedures performed in the current study were approved by the Ethics Committee of Tsinghua University. Written informed consent was obtained from all patients or their families.

\section{Patient consent for publication}

Not applicable.

\section{Competing interests}

The authors declare that they have no competing interests.

\section{References}

1. Hovland S, Muller S, Skomedal H, Mints M, Bergström J, Wallin KL, Karlsen F, Johansson B and Andersson S: E6/E7 mRNA expression analysis: A test for the objective assessment of cervical adenocarcinoma in clinical prognostic procedure. Int J Oncol 36: 1533-1539, 2010.

2. Wolfson IN: Letter: Blind defibrillation. Am J Cardiol 36: 412, 1975.

3. Sankaranarayanan R and Ferlay J: Worldwide burden of gynaecological cancer: The size of the problem. Best Pract Res Clin Obstet Gynaecol 20: 207-225, 2006.

4. Arbyn M, Castellsague X, de Sanjose S, Bruni L, Saraiya M, Bray F and Ferlay J: Worldwide burden of cervical cancer in 2008. Anna Oncol 22: 2675-2686, 2011.

5. Andrae B, Andersson TM, Lambert PC, Kemetli L, Silfverdal L, Strander B, Ryd W, Dillner J, Törnberg S and Sparén P: Screening and cervical cancer cure: Population based cohort study. BMJ 344: e900, 2012.

6. Voulgari A and Pintzas A: Epithelial-mesenchymal transition in cancer metastasis: Mechanisms, markers and strategies to overcome drug resistance in the clinic. Biochim Biophys Acta 1796 75-90, 2009

7. Huang R and Rofstad EK: Cancer stem cells (CSCs), cervical CSCs and targeted therapies. Oncotarget 8: 35351-35367, 2017.
8. Iden M, Fye S, Li K, Chowdhury T, Ramchandran R and Rader JS: The lncRNA PVT1 contributes to the cervical cancer phenotype and associates with poor patient prognosis. PLoS One 11: e0156274, 2016

9. Canuto RA, Muzio G, Salvo RA, Maggiora M, Trombetta A, Chantepie J, Fournet G, Reichert U and Quash G: The effect of a novel irreversible inhibitor of aldehyde dehydrogenases 1 and 3 on tumour cell growth and death. Chem Biol Interact 130-132. 209-218, 2001.

10. Zhang M, Shoeb M, Goswamy J, Liu P, Xiao TL, Hogan D, Campbell GA and Ansari NH: Overexpression of aldehyde dehydrogenase 1A1 reduces oxidation-induced toxicity in SH-SY5Y neuroblastoma cells. J Neurosci Res 88: 686-694, 2010.

11. Ginestier C, Hur MH, Charafe-Jauffret E, Monville F, Dutcher J, Brown M, Jacquemier J, Viens P, Kleer CG, Liu S, et al: ALDH1 is a marker of normal and malignant human mammary stem cells and a predictor of poor clinical outcome. Cell Stem Cell 1: 555-567, 2007.

12. Nalwoga $\mathrm{H}$, Arnes JB, Wabinga $\mathrm{H}$ and Akslen LA: Expression of aldehyde dehydrogenase 1 (ALDH1) is associated with basal-like markers and features of aggressive tumours in African breast cancer. Br J Cancer 102: 369-375, 2010.

13. Sladek NE, Kollander R, Sreerama L and Kiang DT: Cellular levels of aldehyde dehydrogenases (ALDH1A1 and ALDH3A1) as predictors of therapeutic responses to cyclophosphamide-based chemotherapy of breast cancer: A retrospective study. Rational individualization of oxazaphosphorine-based cancer chemotherapeutic regimens. Cancer Chemother Pharmacol 49: 309-321, 2002.

14. Zhao L, Zhang Z, Lou H, Liang J, Yan X, Li W, Xu Y and Ou R: Exploration of the molecular mechanisms of cervical cancer based on mRNA expression profiles and predicted microRNA interactions. Oncol Lett 15: 8965-8972, 2018.

15. Ding J, Xu Z, Zhang Y, Tan C, Hu W, Wang M, Xu Y and Tang J: Exosome-mediated miR-222 transferring: An insight into NF-kappaB-mediated breast cancer metastasis. Exp Cell Res 369: 129-138, 2018.

16. Di Fazio P, Maass M, Roth S, Meyer C, Grups J, Rexin P, Bartsch DK and Kirschbaum A: Expression of hsa-let-7b-5p, hsa-let-7f-5p, and hsa-miR-222-3p and their putative targets HMGA2 and CDKN1B in typical and atypical carcinoid tumors of the lung. Tumour Biol 39: 1010428317728417, 2017.

17. Li Y, Zhao L, Shi B, Ma S, Xu Z, Ge Y, Liu Y, Zheng D and Shi J: Functions of miR-146a and miR-222 in tumor-associated macrophages in breast cancer. Sci Rep 5: 18648, 2015.

18. Xu K, Liang X, Shen K, Sun L, Cui D, Zhao Y, Tian J, Ni L and Liu J: MiR-222 modulates multidrug resistance in human colorectal carcinoma by down-regulating ADAM-17. Exp Cell Res 318: 2168-2177, 2012.

19. Rao X, Di Leva G, Li M, Fang F, Devlin C, Hartman-Frey C, Burow ME, Ivan M, Croce CM and Nephew KP: MicroRNA-221/222 confers breast cancer fulvestrant resistance by regulating multiple signaling pathways. Oncogene 30 : 1082-1097, 2011.

20. Marth C, Landoni F, Mahner S, McCormack M, GonzalezMartin A and Colombo N; ESMO Guidelines Committee: Cervical cancer: ESMO Clinical Practice Guidelines for diagnosis, treatment and follow-up. Ann Oncol 29 (Suppl 4): iv262, 2018.

21. Yamaguchi M, Dieffenbach $\mathrm{CW}$, Connolly R, Cruess DF, Baur W and Sharefkin JB: Effect of different laboratory techniques for guanidinium-phenol-chloroform RNA extraction on A260/A280 and on accuracy of mRNA quantitation by reverse transcriptase-PCR. PCR Methods Appl 1: 286-290, 1992.

22. Heid CA, Stevens J, Livak KJ and Williams PM: Real time quantitative PCR. Genome Res 6: 986-994, 1996.

23. Hakama M, Coleman MP, Alexe DM and Auvinen A: Cancer screening: Evidence and practice in Europe 2008. Eur J Cancer 44: 1404-1413, 2008.

24. Perou CM, Sørlie T, Eisen MB, van de Rijn M, Jeffrey SS, Rees CA, Pollack JR, Ross DT, Johnsen H, Akslen LA, et al: Molecular portraits of human breast tumours. Nature 406: 747-752, 2000.

25. Nozaki Y, Tamori S, Inada M, Katayama R, Nakane H, Minamishima O, Onodera Y, Abe M, Shiina S, Tamura K, et al: Correlation between c-Met and ALDH1 contributes to the survival and tumor-sphere formation of ALDH1 positive breast cancer stem cells and predicts poor clinical outcome in breast cancer. Genes Cancer 8: 628-639, 2017. 
26. Choudhary S, Xiao T, Vergara LA, Srivastava S, Nees D, Piatigorsky J and Ansari NH: Role of aldehyde dehydrogenase isozymes in the defense of rat lens and human lens epithelial cells against oxidative stress. Invest Ophthalmol Vis Sci 46: 259-267, 2005.

27. Quash G, Fournet G, Chantepie J, Gore J, Ardiet C, Ardail D, Michal Y and Reichert U: Novel competitive irreversible inhibitors of aldehyde dehydrogenase (ALDH1): Restoration of chemosensitivity of L1210 cells overexpressing ALDH1 and induction of apoptosis in BAF(3) cells overexpressing bcl(2). Biochem Pharmacol 64: 1279-1292, 2002.

28. Kim MJ, Kim AR, Jeong JY, Kim KI, Kim TH, Lee C, Chung K, Ko YH and An HJ: Correlation of ALDH1 and notch3 expression: Clinical implication in ovarian carcinomas. J Cancer 8: 3331-3342, 2017.

29. Zheng R, Wang J, Wu Q, Wang Z, Ou Y, Ma L, Wang M, Wang J and Yang Y: Expression of ALDH1 and TGF $\beta 2$ in benign and malignant breast tumors and their prognostic implications. Int J Clin Exp Pathol 7: 4173-4183, 2014.

30. House CD, Jordan E, Hernandez L, Ozaki M, James JM, Kim M, Kruhlak MJ, Batchelor E, Elloumi F, Cam MC and Annunziata CM: NFאB promotes ovarian tumorigenesis via classical pathways that support proliferative cancer cells and alternative pathways that support ALDH+ cancer stem-like cells. Cancer Res 77: 6927-6940, 2017.

31. Wang L, Liu Y, Zhou Y, Wang J, Tu L, Sun Z, Wang X and Luo F. Zoledronic acid inhibits the growth of cancer stem cell derived from cervical cancer cell by attenuating their stemness phenotype and inducing apoptosis and cell cycle arrest through the Erk1/2 and Akt pathways. J Exp Clin Cancer Res 38: 93, 2019.

32. Kaehler M, Ruemenapp J, Gonnermann D, Nagel I, Bruhn O, Haenisch S, Ammerpohl O, Wesch D, Cascorbi I and Bruckmueller H: MicroRNA-212/ABCG2-axis contributes to development of imatinib-resistance in leukemic cells. Oncotarget 8: 92018-92031, 2017.
33. Wu Q, Guo L, Jiang F, Li L, Li Z and Chen F: Analysis of the miRNA-mRNA-lncRNA networks in ER+ and ER- breast cancer cell lines. J Cell Mol Med 19: 2874-2887, 2015.

34. Liu X, Yu J, Jiang L, Wang A, Shi F, Ye H and Zhou X: MicroRNA-222 regulates cell invasion by targeting matrix metalloproteinase 1 (MMP1) and manganese superoxide dismutase 2 (SOD2) in tongue squamous cell carcinoma cell lines. Cancer Genomics Proteomics 6: 131-139, 2009.

35. Aherne ST, Smyth P, Freeley M, Smith L, Spillane C, O'Leary J and Sheils O: Altered expression of mir-222 and mir-25 influences diverse gene expression changes in transformed normal and anaplastic thyroid cells, and impacts on MEK and TRAIL protein expression. Int J Mol Med 38: 433-445, 2016.

36. Lloyd KA, Moore AR, Parsons BN, O'Hara A, Boyce M, Dockray GJ, Varro A and Pritchard DM: Gastrin-induced miR-222 promotes gastric tumor development by suppressing p27kip1. Oncotarget 7: 45462-45478, 2016.

37. Choi B, Yu J, Han TS, Kim YK, Hur K, Kang BC, Kim WH, Kim DY, Lee HJ, Kim VN and Yang HK: Gastric carcinogenesis in the miR-222/221 transgenic mouse model. Cancer Res Treat 49: 150-160, 2017.

38. Ying X, Wu Q, Wu X, Zhu Q, Wang X, Jiang L, Chen X and Wang $\mathrm{X}$ : Epithelial ovarian cancer-secreted exosomal miR-222-3p induces polarization of tumor-associated macrophages. Oncotarget 7: 43076-43087, 2016.

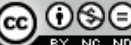

This work is licensed under a Creative Commons Attribution-NonCommercial-NoDerivatives 4.0 International (CC BY-NC-ND 4.0) License. 